\title{
Editorial
}

\section{Visual Inspection with Acetic Acid for Cervical Cancer Screening: Bangladesh Perspective}

D Zeba

Cervical cancer is the second most common cancer among women in Bangladesh ${ }^{1}$. Cervical cancer constitutes $25 \%$ of all female cancer and accounts for 17,686 new cases and 10,364 deaths annually in Bangladesh $^{2}$. Cervical cancer is a highly preventable disease. Approximately 54.4 million women aging over 15 years are potentially at risk $^{1}$. The annual crude incidence rate of invasive cervical cancer in Bangladesh is 15.9 per 100,000 , which is lower than the overall annual incidence rate of South Asia 17.1 per 100,000 . But it is higher than the global annual crude incidence rate of 15.1 per $100,000^{3}$. More than $80 \%$ of patients are diagnosed when they are clinically advanced and in inoperable stage ${ }^{4}$. This causes unbearable distress for the family and treatment burden for the nation.

Invasive cervical cancers are usually preceded by a long phase of preinvasive disease (Cervical Intraepithelial Neoplasia - CIN). Overall 99.7 percent of patients with CIN and invasive cancer are found to be positive with HPV DNA (Human papilloma virus). Among HPV types, 16, 18, 31, 33, 35, 45, 56 are diagnosed as high oncogenic risk. HPV is so common that about half of all men and more than 3 out of 4 women have HPV infection at some time in their life. Fortunately, most of the infections go away spontaneously. But high oncogenic type may proceed to CIN, then invasive cancer ${ }^{5}$. As the risk factors are known and there is a long preinvasive period about 1017 years, an effective screening method can reduce the incidence of cervical cancer about $80 \%$ and death by $70 \%$.

There are so many screening methods effective and working throughout the world. Among them, cervical cytology that is Pap's smear is widely accepted worldwide with high specificity and sensitivity about $60 \%$. Due to constraint of resource personals and considering cost-effectiveness, it was not possible to establish Pap's smear for cervical cancer screening in our country.

Population based cervical cancer screening was initiated in Bangladesh in 2004 as a pilot study and in 2005 as a national programme ${ }^{7}$. Visual inspection after

1. Dr. Dilruba Zeba, MBBS, DGO, MCPS, FCPS (Gynae \& Obst), Associate Professor, Department of Gynae and Obst, Faridpur Medical College.

Address of correspondence :

Dr. Dilruba Zeba, MBBS, DGO, MCPS, FCPS (Gynae \& Obst), Associate Professor, Department of Gynae and Obst, Faridpur Medical College, Faridpur, Bangladesh. Mobile: +8801712090825 ,

E-mail: dilruba_zeba@yahoo.com application of acetic acid (VIA) is a simple and affordable screening test with acceptable sensitivity and specificity in the range $56-77 \%$ and $64-86 \%$ respectively in a research setting ${ }^{8}$. A population-based study conducted in Bangladesh observed that the sensitivity and specificity of VIA performed by trained paramedics were $79 \%$ and $57.4 \%$ respectively ${ }^{9}$. Bangladesh is one of the first countries in the world to introduce VIA as the screening test for its national cervical cancer screening programme.

VIA screening programme is provided through the existing healthcare infrastructure in Bangladesh. VIA is being done by trained nurses at all medical colleges, district hospitals, maternal and child welfare centers (MCWCs) and selective upazila health complexes ${ }^{10}$. A national curriculum on cervical screening programme guideline and standards (both in English and Bengali) was developed and approved by the National Technical Review Committee of Director General of Health Services ${ }^{11}$.

The target population for VIA screening is apparently healthy, married women aged 30 years or married for more than 10 years. A public education programme using posters and pamphlets in the healthcare facilities up to community clinics has been organized to create awareness of cervical cancer prevention through VIA screening in the public health services. All VIApositive women are being referred with a pink referral card to the colposcopy clinics at BSMMU or medical college hospitals. These centers are providing colposcopy facilities for further evaluation and treatment facilities for all cases of CIN. Most of the centers are adopting the ideology of 'See and Treat' policy to reduce the drop out rate. Women with negative VIA get blue card and are advised to come back for repeat checkup after 5 years. A manual register is kept at each VIA screening center ${ }^{11}$.

Other than Thailand, Bangladesh is the only country in South Asia that has introduced a VIA based screening programme for cervical cancer. The VIA test positivity is around $5 \%$ in various population based studies.

For screening of cervical cancer, VIA has been established as the most effective, low cost effective with specificity and sensitivity near to Pap's smear. By this time, Government has already established the VIA centers, trained manpower, effective referral system, treatment facilities for VIA positive women by 
colposcopy clinic and finally very realistic monitoring system. And now it is the time and issue to spread the screening programme among our population and increase the coverage of screening of cervical cancer. So that we can reduce the mortality and morbidity related to cervical cancer.

\section{References :}

1. Bruni L, Barrionuevo-Rosas L, Albero G et al. ICO information centre on HPV and cancer (HPV information centre). Human papillomavirus and related diseases in Bangladesh. Summary Report 2015-03-20. Available at http://www.hpvcentre.net/ statistics/ reports/BGD.pdf. Accessed November 9, 2015.

2. Ferlay J, Shin HR, Bray F. GLOBOCAN 2008: Cancer incidence and mortality worldwide. IARC Cancer Base. No. 10. Lyon, France: IARC Press, 2010.

3. Bruni L, Barrionuevo-Rosas L, Albero G. ICO information centre on HPV and cancer (HPV information centre). Human papillomavirus and related diseases in the world. Summary Report 2015-04-08. Available at http://www.hpvcentre.net/statistics/ reports/XWX.pdf. Accessed November 9, 2015.

4. Akhter PS, Uddin MM, Sharma SK. Patterns of malignant neoplasm. A three year study. Bangladesh Med J 1998;27: 29-32.

5. Cervical cancer screening and prevention. Practice Bulletin No. 157. American College of Obstetricians and Gynecologists. Obstet Gynecol 2016:127:e1- 20.

6. Schiffman M, Solomon D. Clinical practice. Cervical-cancer screening with human papilloma virus and cytologic cotesting. N Engl J Med 2013;369:2324-31.

7. Ahmed T, Ashrafunnessa KS, Rahman J. Development of a visual inspection programme for cervical cancer prevention in Bangladesh. Reprod Health Matters 2008; 16:78-85.

8. Sankaranarayanan R, Basu P, Wesley RS, Mahe C, Keita N, Mbalawa CC, et al.; IARC Multicentre Study Group on Cervical Cancer Early Detection. Accuracy of visual screening for cervical neoplasia: results from an IARC Multicentre Study in India and Africa. Int J Cancer 2004; 110:907-913.

9. Rahman A. Visual inspection aided with acetic acid: a feasible approach for cervical cancer screening in Bangladesh [Abstract 055(016)]. Abstract presented at the $12^{\text {th }}$ ASCON Conference, Dhaka, Bangladesh, 9-12 February 2009.

10. Basu P, Nessa A, Majid M, Rahman JN, Ahmed T. Evaluation of the National Cervical Cancer Screening Programme of Bangladesh and the formulation of quality assurance guidelines. BMJ Sexual \& Reproductive Health. 2010 Jul 1;36(3):131-4.

11. Nessa A, Hussain MA, Rahman JN, Rashid MH, Muwonge R, Sankaranarayanan R. Screening for cervical neoplasia in Bangladesh using visual inspection with acetic acid. International Journal of Gynecology \& Obstetrics. 2010 Nov 1;111(2):115-8. 